\title{
COMPARAÇÃO ENTRE BIODIGESTORES OPERADOS EM ESCALA PILOTO PARA PRODUÇÃO DE BIOGÁS ALIMENTADO COM ESTRUME BOVINO
}

\section{COMPARISON BETWEEN BIODIGESTERS OPERATED IN PILOT SCALE FOR BIOGAS PRODUCTION FED WITH BOVINE MANURE}

\section{Rodrigo de Freitas Bueno}

Bacharel em Biologia. Especialista em Engenharia de Controle da Poluição Ambiental pela Faculdade de Saúde Pública da USP. Mestrando em Saúde Pública e Engenharia Ambiental e Tecnologias de Saneamento pela Faculdade de Saúde Pública da USP (FSP/USP). e-mail: robueno@usp.br

\section{RESUMO}

Objetiva-se, aqui, um estudo comparativo entre dois biodigestores operados em escala piloto para produção de biogás e redução de material orgânico a partir de estrume bovino em duas concentrações diferentes, por meio de variáveis validadas para o tratamento de lodo anaeróbio de estações de tratamento de esgoto sanitário. Após o período de biodegradação ( 29 dias), o volume produzido de biogás foi maior no biodigestor I (mais diluído), e a remoção de material orgânico medida na forma de Demanda Química de Oxigênio (DQO) e Demanda Bioquímica de Oxigênio (DBO) foi de 51-61,6\% e 26,9-43,8\% nos biodigestores I e II, respectivamente. As variáveis de controle utilizadas para realização do presente estudo mostraram-se adequadas, assim como o uso do teste de Atividade Metanogênica Específica (AME) onde os valores para os biodigestores I e II, referentes ao volume de gás metano produzido nas Condições Normais de Temperatura e Pressão (CNTP), foram de 36 e $17 \mathrm{~mL}$ $\mathrm{CH}_{4} \cdot \mathrm{g}^{-1} \mathrm{SSV} \cdot \mathrm{h}^{-1}$, respectivamente.

Palavras-chave: Atividade metanogênica específica. Biogás. Digestão anaeróbia. Biomassa.

\section{ABSTRACT}

Comparative study between two biodigesters operated on a pilot scale for biogas production and organic material reduction from bovine manure at two different concentrations, through variables validated for the treatment of anaerobic 
sludge from station for biological sanitary sewage treatment. After the biodegradation period (29 days), the volume of biogas produced was higher in the biodigester I (more diluted), and removal of organic matter measured as Chemical Oxygen Demand (COD) and Biochemical Oxygen Demand (BOD) was 51-61,6\% and 26.9$43.8 \%$ in the biodigesters I and II, respectively. The analysis of the Specific Methanogenic Activity (SMA) in the biodigester I and II were 36 and $17 \mathrm{~mL}$ CH4.g1 SSV.h-1 of methane gas produced Normal Temperature and Pressure (NTP), respectively. The control variables used in this study were suitable.

Keywords: Specific methanogenic activity. Biogas. Anaerobic digestion. Biomass.

\section{INTRODUÇÃO}

Nos últimos anos, o setor agropecuário do Brasil vem se modernizando e provocando aumento significativo na demanda de energia e no volume de resíduos, ocasionando desconforto e perigo à saúde, devido o alto teor de substâncias patogênicas presentes nestes resíduos (NASCIMENTO, 1995). Uma alternativa eficiente para estes problemas é a reciclagem controlada desses resíduos, por meio da biodigestão anaeróbia ocorrida em biodigestores (LUCAS JR. e SILVA, 1998). A utilização dos biodigestores no meio rural tem merecido destaque devido aos aspectos de saneamento e energia, além de estimular a reciclagem orgânica e de nutrientes.

$\mathrm{O}$ aspecto saneamento surge no instante em que se isolam os resíduos do homem e dos animais, proporcionando a diminuição de moscas e odores, permitindo também a redução das demandas química e bioquímica de oxigênio e de sólidos, tornando mais disponíveis os nutrientes para as plantas (biofertilizante). A redução de parasitas e patógenos do homem e dos animais também foram observadas em trabalhos realizados pelo Programa de Pesquisas em Saneamento Básico (PROSAB, 2003); (LUCAS JR. et al., 1998).

Alguns resíduos produzidos no meio rural, como os dejetos de ruminantes, sofrem um pré-tratamento no trato digestivo dos animais, que são verdadeiras câmaras naturais de fermentação anaeróbia onde se desenvolvem harmonicamente as bactérias. Ao se colocar, portanto, estes resíduos em biodigestor, em pouco tempo haverá produção de biogás, sendo um produto de grande potencial energético (LUCAS JR. et al. 1993). Na engenharia ambiental, cada vez mais os fundamentos da digestão anaeróbia vêm sendo aplicados na concepção de sistemas de tratamento de resíduos sólidos visando o aproveitamento energético do biogás (LUCAS JR. e SANTOS, 2000).

A digestão anaeróbia é um processo de estabilização biológica no qual um consórcio de diferentes tipos de microrganismos, na ausência de oxigênio molecular, promove a transformação de compostos orgânicos complexos em produtos mais simples como metano e gás carbônico. Para que essa transformação ocorra, distingui- 
se três etapas principais no processo global da conversão da matéria orgânica: I) hidrólise, II) acidogênese e acetogênese e III) metanogênese (Figura 1).

$\mathrm{Na}$ hidrólise a maioria dos compostos orgânicos complexos e polimerizados devem ser degradados em produtos mais simples. Na acidogênese, os compostos orgânicos mais simples são convertidos, por meio das bactérias acidogênicas, em ácidos graxos voláteis de cadeia curta (acético, butírico e propiônico), ácido lático e compostos minerais. $\mathrm{Na}$ etapa seguinte, a acetogênese, ocorre a conversão dos produtos da acidogênese em compostos que formam os substratos para a produção de metano: acetato, dióxido de carbono e hidrogênio. Finalmente na última etapa, a metanogênese, considerada a mais importante e sensível, os ácidos voláteis são consumidos como alimento pelas arqueas metanogênicas e são produzidos metano e dióxido de carbono. Algum metano extra é produzido da conversão do dióxido de carbono e hidrogênio produzidos na acetogênese (PROSAB, 2003).

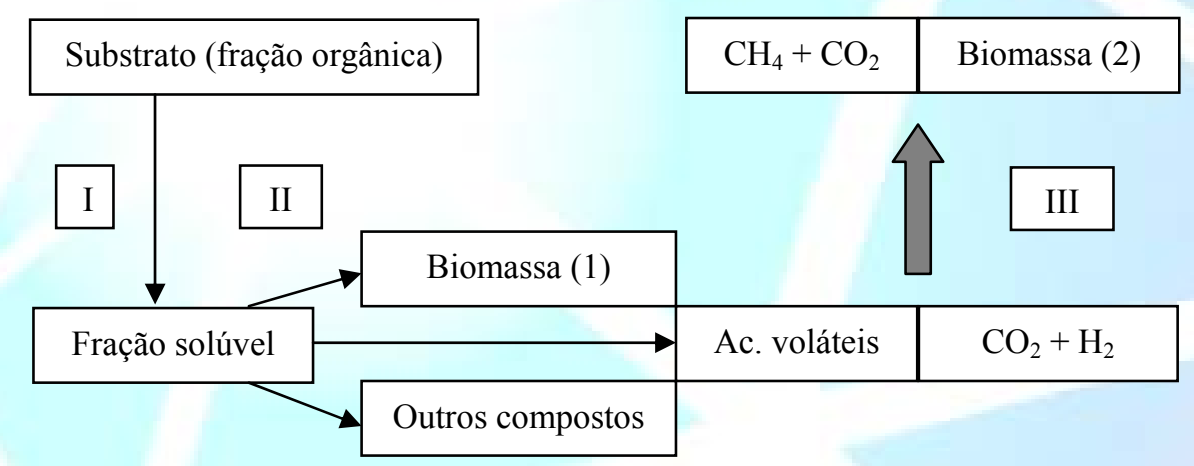

Figura 1. Resumo esquemático do processo anaeróbio. I- hidrólise; II- acidogênese e acetogênese; IIImetanogênese. Biomassa (1): crescimento consorciado de bactérias hidrolíticas e acidogênicas. Biomassa (2): microrganismos metanogênicos.

Cada uma dessas etapas deve ser mantida em equilíbrio dinâmico a fim de que a metanogênese ocorra à taxa máxima. A manutenção desse equilíbrio está relacionada à natureza do substrato e a intensidade e disponibilidade de $\mathrm{H}_{2}$ (hidrogênio), pois este deve ser continuamente removido do meio para assegurar que a produção de ácido acético não seja interrompida ou diminua drasticamente. Essa condição é essencial para que a fermentação metanogênica prevaleça, sendo $\mathrm{H}_{2}$ e ácido acético, os mais importantes, responsáveis por cerca de $70 \%$ do gás metano gerados no biodigestor (FORESTI, 1994).

Todos os microrganismos envolvidos na digestão anaeróbia são especializados e cada grupo atua em reações específicas. Nos biodigestores, a formação de metano (componente principal do biogás) é altamente desejável, porém os microrganismos metanogênicos são mais sensíveis do que os hidrolíticos ou acidogênicos às condições desfavoráveis do meio. As condições ao bom funcionamento do processo, portanto, devem favorecer especialmente o desenvolvimento desses microrganismos que são anaeróbios estritos. Estes são de crescimento lento e apresentam grande sensibilidade às condições externas. Em biodigestores operados na faixa mesofílica 
$\left(30\right.$ a $35^{\circ} \mathrm{C}$ ), as arqueas metanogênicas predominantes são os Methanobacyerium, Methanobrevibacter e Methanospirillum, utilizando o hidrogênio e o $\mathrm{CO}_{2}$, como substrato e os Methanosarcina e Methanothrix, principalmente gerando metano a partir de acetato. $\mathrm{O}$ crescimento dos microrganismos metanogênicos é ótimo na faixa de $\mathrm{pH}$ de 6,8 a 7,4, sendo os metanogênicos acetotróficos os mais susceptíveis a níveis reduzidos de $\mathrm{pH}$, em que sua taxa de crescimento é máxima por volta do $\mathrm{pH}$ neutro, caindo consideravelmente para valores de pH abaixo de 6,6 (DOHÁNYOS e ZÁBRANSKÁ, 2001).

Objetiva-se, aqui, um estudo comparativo entre dois biodigestores operados em escala piloto para produção de biogás a partir de estrume bovino em duas concentrações: Biodigestor I operado na proporção (1:2), sendo (1 estrume: 2 água) mais diluído, e Biodigestor II operado na proporção (1:1), sendo (1 estrume: 1 água), portanto, mais concentrado. Por meio de variáveis validadas para o tratamento de lodo anaeróbio de estações de tratamento de esgoto sanitário, foram analisados os principais fatores que afetam a fermentação anaeróbia, visando à eficiência entre as concentrações para produção do biogás e redução de matéria orgânica medidas na forma de sólidos voláteis, DQO e DBO.

\section{MATERIAIS E MÉTODOS}

\subsection{Variáveis de Controle}

As principais variáveis de controle para produção de biogás foram realizadas conforme descrito no Standard Methods for Examination of Water and Wasterwater (APHA, 2005):

I- DQO (método colorimétrico, espectrofotômetro HACH DR2010) e $\mathrm{DBO}_{5,20}$ esta utilizada para medição da matéria orgânica biodegradável;

II- Série de sólidos (correspondem a toda matéria que permanece como resíduo, após evaporação, secagem ou calcinação da amostra a uma temperatura pré-estabelecida durante um tempo fixado), dentro dos sólidos totais a fração de sólidos em suspensão voláteis (SSV), será utilizada para expressar unidade de biomassa representando a fração orgânica da biomassa, já que a matéria orgânica pode ser volatilizada (SPERLING, 1996);

III- Relação Alcalinidade e Ácidos Orgânicos Voláteis (AOV) foram determinados por titulometria. Estas variáveis devem ser controladas, pois ocorre acúmulo de ácidos orgânicos voláteis no reator consumindo alcalinidade, inibindo o efeito tampão do meio e conseqüentemente diminuindo o $\mathrm{pH}$ desestabilizando o processo. Para evitar essa variação, se recomenda uma relação de 10:1, ou seja, a concentração de alcalinidade tem que estar aproximadamente dez (10) vezes maiores que a 
concentração de AOV, esta relação garante um efeito tampão no meio mantendo o $\mathrm{pH}$ neutro, proporcionando um bom funcionamento do biodigestor (CHERNICHARO, 1997).

\subsection{Aclimatação}

Para a adaptação às condições do teste os substratos foram colocados nos biodigestores vedados e permanecendo em repouso por 24 horas a temperatura de 20 ${ }^{\circ} \mathrm{C}$, para remoção de traços de $\mathrm{O}_{2}$.

\subsection{Biodigestores}

Os biodigestores são constituídos por duas partes distintas: câmara de fermentação e gasômetro (Figura 2). A câmara de fermentação comporta a mistura do material orgânico com água formando um meio anaeróbio, onde as arqueas metanogênicas atuarão resultando na produção do biogás. A alimentação é realizada integralmente pela torneira para este fim visando à fermentação de todo o material $\approx$ 30 dias. A câmara de fermentação dispõe de um agitador que tem função de evitar que o $\mathrm{CO}_{2}$, produzido na biodigestão, forme bolhas estacionárias no afluente (material orgânico diluído). A ocorrência de tais bolhas dificulta a ação das arqueas metanogênicas, diminuindo a velocidade do processo.

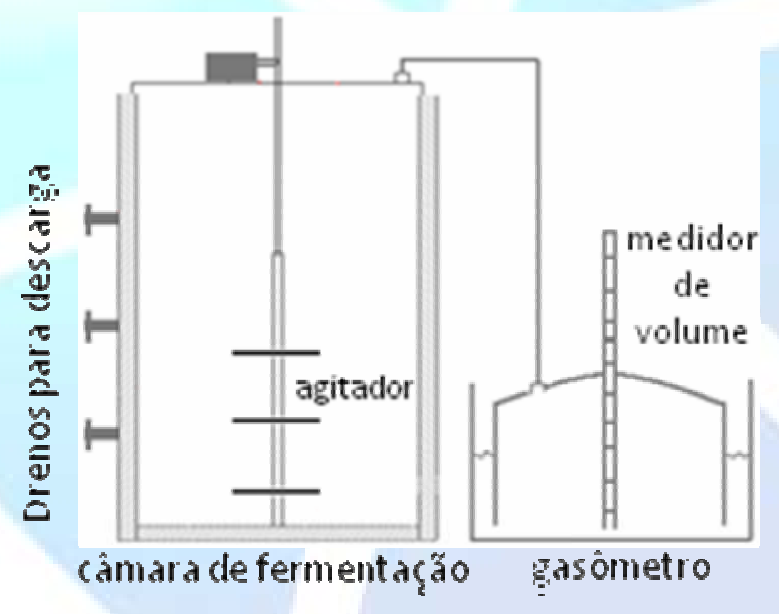

Figura 2. Esquema do Biodigestor com medidor de biogás

A câmara possui, ainda, 03 drenos para descarga. $\mathrm{O}$ dreno permite a descarga do material orgânico e retirada de amostras para controle em diferentes níveis. Para captação e armazenamento do gás, foi utilizado um gasômetro, que é constituído de um cilindro de plástico com medidor de volume em litros e colocado em recipiente com solução de hidróxido de sódio $(\mathrm{NaOH}) 3 \%$ e indicador fenolftaleína (SOARES, 1997). 
Foram utilizados dois biodigestores em batelada, com capacidade de 10 litros cada, acoplados aos seus respectivos gasômetros. As leituras do volume de gás foram corrigidas para a pressão atmosférica normal, para compensar a coluna de líquido no tubo do gasômetro. A biomassa foi de estrume bovino fresca, preparada na proporção de 1 (estrume): 1 (água), e na proporção 1 (estrume): 2 (água), colocados nos biodigestores. Para medição das temperaturas interna e externa dos reatores, contouse com o auxílio de um termômetro digital. A temperatura dos biodigestores foi controlada por resistências conectadas a um dimer, onde se manteve em torno de $35^{\circ} \mathrm{C}$. Assim o biodigestor I foi operado com o estrume (1:2) mais diluído e biodigestor II com o estrume (1:1) mais concentrado.

\subsection{Cálculo da Biomassa e Produção de Biogás}

A biomassa foi calculada relacionando a concentração de sólidos suspensos voláteis (SSV) g. $\mathrm{L}^{-1}$ e o volume da mistura final do substrato. A Atividade Metanogênica Específica (AME) de um substrato é um parâmetro de controle importante no processo de digestão anaeróbia, possibilitando determinar as condições de partida de um biodigestor, bem como a evolução e possíveis alterações na qualidade desse substrato. Este teste fornece a taxa de produção de metano ou a taxa de consumo de substrato metanogênico por unidade de biomassa microbiana (MONTEGGIA, 1997). O método utilizado para o teste de AME foi o volumétrico, de medição direta de volume de metano por meio da lavagem do biogás em solução de hidróxido de sódio $3 \%(\mathrm{~m} / \mathrm{v})$, relacionando-se a quantidade de metano produzido em $\mathrm{mL}$ pela biomassa em grama de SSV e pelo tempo, em horas, de acordo com a seguinte expressão (MONTEGGIA, 1997):

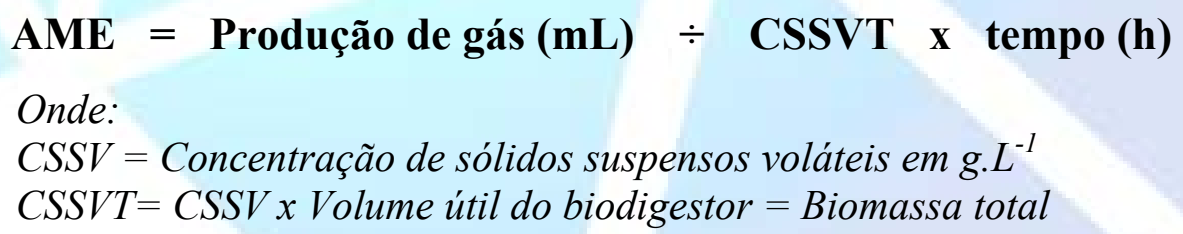

\subsection{Eficiência do Biodigestor}

Para se conhecer a eficiência do biodigestor ou redução de sólidos voláteis, calculou-se a Taxa de Aplicação de Material Orgânico (TAMO) e a Velocidade de Decomposição de Sólidos Voláteis (VDSV); a eficiência foi então determinada por VDSV $\div$ TAMO. A TAMO refere-se à quantidade de sólidos voláteis aplicadas no biodigestor em relação ao volume do mesmo, num determinado intervalo de tempo e está associada ao tempo de retenção e à concentração de sólidos voláteis. Essa taxa é calculada em unidade de massa por volume e tempo (BATISTA, 1981):

\section{TAMO $=$ Sólido Volátil Total Inicial $\div$ Capacidade do Biodigestor $\mathbf{x}$ Tempo}


Os biodigestores usados neste estudo são de regime de batelada, não precisando, portanto, de abastecimento diário. O tempo considerado foi de 29 dias, tempo necessário para a realização de cada teste. A velocidade de decomposição de sólidos voláteis está relacionada à quantidade de sólidos voláteis que se degrada com a biodigestão. É, assim, obtida (em unidade de massa por volume de biodigestor e tempo) pela fórmula (BATISTA, 1981):

\section{VDSV $=\left(S_{\text {SVT }}\right.$ Inicial $\left.-S_{\text {Final }}\right) \div$ Capacidade do Biodigestor $\mathbf{x}$ Tempo \\ Onde: \\ VDSV = Velocidade de decomposição de sólidos voláteis \\ $S V T=$ Sólidos voláteis totais}

\section{RESULTADOS E DISCUSSÃO}

\subsection{Caracterização Inicial da Biomassa}

Para o início do estudo foram realizados testes analíticos na amostra de estrume fresco diluído (1:1), obtendo-se informações sobre as variáveis DQO, nitrogênio, fósforo e $\mathrm{pH}$, como demonstrado na Tabela 1.

Tabela 1 - Análise de caracterização

\begin{tabular}{cccccc}
\hline Amostra & $\begin{array}{c}\mathrm{T}^{\circ} \mathbf{C} \\
\text { (média) }\end{array}$ & $\begin{array}{c}\mathrm{DQO}^{(1)} \\
\mathbf{m g} \cdot \mathrm{L}^{-1}\end{array}$ & $\begin{array}{c}\mathbf{N}^{(2)} \\
\mathbf{m g} \cdot \mathrm{L}^{-1}\end{array}$ & $\begin{array}{c}\mathbf{P}^{(3)} \\
\mathbf{m g} \cdot \mathrm{L}^{-1}\end{array}$ & $\mathrm{pHi}^{(4)}$ \\
\hline \multirow{2}{*}{ Bruta } & 25 & 119000 & 10554 & 665 & 8,80 \\
\hline
\end{tabular}

(1) Demanda química de oxigênio; ${ }^{(2)}$ Nitrogênio total; ${ }^{(3)}$ Fósforo total; ${ }^{(4)} \mathrm{pH}$ inicial.

Segundo Chernicharo (1997), a relação DQO: N: P deve ser na ordem de (350:7:1) e a falta destes nutrientes reduz a atividade metabólica dos microrganismos, conseqüentemente reduzindo a eficiência na produção do biogás. Os valores obtidos para o estrume bovino demonstraram relação de aproximadamente (350: 31:2), portanto, não havendo necessidade de adição de nutrientes. Verificou-se que o $\mathrm{pH}$ do estrume bovino é alcalino maior do que 8,5. O mesmo foi inicialmente corrigido com ácido fosfórico para aproximadamente 7,0 , favorecendo uma condição máxima de crescimento das arqueas metanogênicas (DOHÁNYOS e ZÁBRANSKÁ, 2001).

\subsection{Biodigestores e Gasômetros de Bancada}

Os biodigestores foram mantidos a temperaturas médias de $35{ }^{\circ} \mathrm{C}$ e o período de incubação foram de 29 dias. A Tabela 2 apresenta os resultados obtidos na produção de biogás durante o período do teste. Durante os 29 dias, a produção acumulativa ( $\left.\mathrm{V}_{\text {produzido }}\right)$ de biogás no biodigestor I foi maior do que no biodigestor II, sendo que atingiu a eficiência na produção acumulativa máxima nos $8^{\circ}$ e $9^{\circ}$ dia e 
depois decresceu. Já no biodigestor II, a produção de biogás cumulativa foi sempre menor em relação ao biodigestor I, o que se observa quando se comparou o volume de produção entre os biodigestores (Tabela 2). A produção máxima diária ocorreu no $15^{\circ}$ dia.

Tabela 2 - Produção de biogás no período de 29 dias nos biodigestores I e II

\begin{tabular}{|c|c|c|c|c|}
\hline \multirow[b]{2}{*}{ Dia } & \multicolumn{2}{|c|}{ Biodigestor I } & \multicolumn{2}{|c|}{ Biodigestor II } \\
\hline & $\begin{array}{c}\mathrm{V}_{\text {diário }} \\
\text { (Litros) }\end{array}$ & $\begin{array}{l}\text { V }_{\text {produzido }} \\
\text { (Litros) }\end{array}$ & $\begin{array}{c}\mathrm{V}_{\text {diário }} \\
\text { (Litros) }\end{array}$ & $\begin{array}{l}\text { V }_{\text {produzido }} \\
\text { (Litros) }\end{array}$ \\
\hline 1 & 6,5 & 6,5 & 2,5 & 2,5 \\
\hline 2 & 14,7 & 21,2 & 2,4 & 4,8 \\
\hline 3 & 14,3 & 35,5 & 1,8 & 6,6 \\
\hline 4 & 8,5 & 44,0 & 0,0 & 6,6 \\
\hline 5 & 8,5 & 52,5 & 1,5 & 8,1 \\
\hline 6 & 6,0 & 58,5 & 0,6 & 8,6 \\
\hline 7 & 12,5 & 71,0 & 0,3 & 8,9 \\
\hline 8 & 8,5 & 79,5 & 0,3 & 9,2 \\
\hline 9 & 6,0 & 85,5 & 0,9 & 10,1 \\
\hline 10 & 4,2 & 89,7 & 3,2 & 13,4 \\
\hline 11 & 8,5 & 98,2 & 2,4 & 15,7 \\
\hline 12 & 8,5 & 106,7 & 2,9 & 18,6 \\
\hline 13 & 7,0 & 113,7 & 8,2 & 26,9 \\
\hline 14 & 3,3 & 117,0 & 12,9 & 39,8 \\
\hline 15 & 3,5 & 120,5 & 14,6 & 54,4 \\
\hline 16 & 1,5 & 122,0 & 10,0 & 64,4 \\
\hline 17 & 3,0 & 125,0 & 10,3 & 74,7 \\
\hline 18 & 3,3 & 128,3 & 3,4 & 78,1 \\
\hline 19 & 3,3 & 131,5 & 3,4 & 81,5 \\
\hline 20 & 0,9 & 132,4 & 2,1 & 83,6 \\
\hline 21 & 3,0 & 135,4 & 7,1 & 90,6 \\
\hline 22 & 3,0 & 138,4 & 4,7 & 95,4 \\
\hline 23 & 2,2 & 140,6 & 4,0 & 99,4 \\
\hline 24 & 2,0 & 142,6 & 3,8 & 103,2 \\
\hline 25 & 4,5 & 147,1 & 3,8 & 107,0 \\
\hline 26 & 1,8 & 148,9 & 1,2 & 108,2 \\
\hline 27 & 2,2 & 151,1 & 1,2 & 109,4 \\
\hline 28 & 3,0 & 154,1 & 1,2 & 110,5 \\
\hline 29 & 2,0 & 156,1 & 1,2 & 111,7 \\
\hline Total & & 156,1 & & 111,7 \\
\hline
\end{tabular}

Segundo Chernicharo (1997), quando o substrato esta mais diluído facilita a "quebra" da matéria orgânica utilizada pelos microrganismos anaeróbios. Estudos realizados pelo PROSAB (2003) citam a importância da fase de hidrólise, sendo considerado um dos passos limitantes do processo na digestão anaeróbia, o que justifica os resultados obtidos. Quando se compara a produção total nesse período, observa-se que não houve diferença na produção total de biogás, sendo: biodigestor I 156,1 e biodigestor II 111,7 litros. 
Com os valores obtidos na Tabela 2 foi elaborada a Figura 3, onde apresenta a produção diária de biogás dos biodigestores I e II no período de 29 dias do estudo. Onde mais uma vez podemos visualizar a afirmação acima.

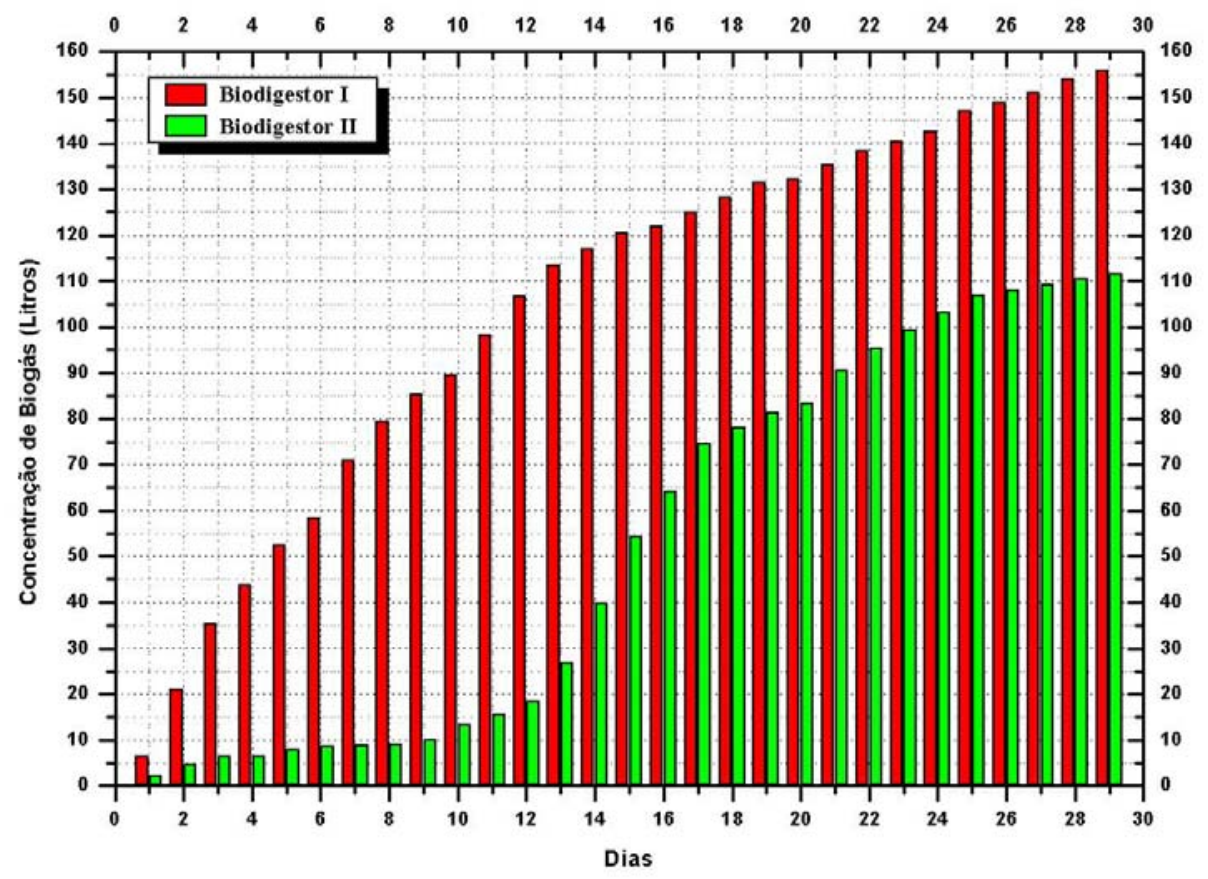

Figura 3. Comparação da produção de biogás entre os biodigestores I e II

\subsection{Eficiência do Biodigestor}

Com os dados da Tabela 3 calcularam-se as eficiências dos biodigestores ou redução de sólidos voláteis, com base nos valores de VDSV e TAMO considerando o tempo de 29 dias para o teste com a temperatura de $35{ }^{\circ} \mathrm{C}$. Verificou-se que no biodigestor I a eficiência foi baixa, (sendo a recomendada superior a 30\%) (BATISTA, 1981), já o biodigestor II encontra-se em 53\%.

Tabela 3 - Eficiência dos Biodigestores baseada na redução de sólidos voláteis.

\begin{tabular}{ccccccccc}
\hline BIODIGESTOR & $\begin{array}{c}\text { Temp. } \\
{ }^{\circ} \mathbf{C} \\
\text { (média) }\end{array}$ & $\begin{array}{c}\mathbf{S T i}^{(1)} \\
\mathbf{g} \cdot \mathbf{L}^{-1}\end{array}$ & $\begin{array}{c}\mathbf{S T f}^{(2)} \\
\mathbf{g} \cdot \mathbf{L}^{-1}\end{array}$ & $\begin{array}{c}\mathbf{S V i}^{(3)} \\
\mathbf{g} \cdot \mathbf{L}^{-1}\end{array}$ & $\begin{array}{c}\mathbf{S V f}^{(4)} \\
\mathbf{g} \cdot \mathbf{L}^{-1}\end{array}$ & TAMO $^{(5)}$ & VDSV $^{(6)}$ & $\begin{array}{c}\text { Eficiência } \\
\%\end{array}$ \\
\hline I & 35 & 73,5 & 68,2 & 62,7 & 52 & 0,22 & 0,037 & 17 \\
II & 35 & 115,5 & 55,25 & 95 & 44,25 & 0,33 & 0,175 & 53 \\
\hline
\end{tabular}

(1) Sólidos totais inicial; (2) Sólidos totais final; (3) Sólidos voláteis inicial; (4) Sólidos voláteis final; (5) Taxa de aplicação de material orgânico; (6) Velocidade de decomposição de sólidos voláteis. 
A Figura 4 apresenta os resultados da série de sólidos durante o período de biodegradação, verifica-se que não houve redução nas concentrações de sólidos, provavelmente pela alta concentração de substrato e pelo baixo tempo de retenção nos biodigestores. Quando se compara a redução de sólidos voláteis entre os biodigestores, observa-se maior redução no biodigestor II (SSV II), o que justifica maior eficiência citada no item anterior.

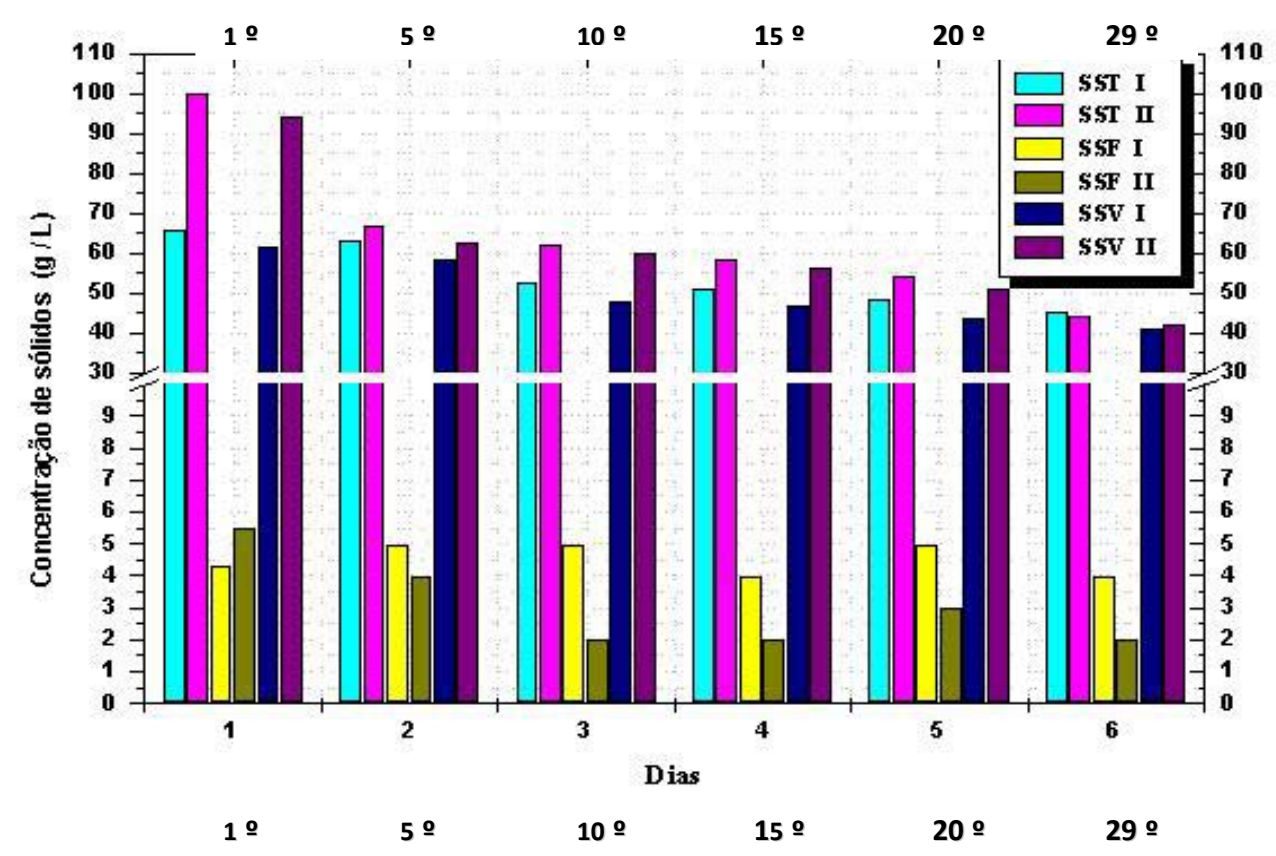

Figura 4. Comparativo da série de sólidos nos biodigestores I e II durante o período de biodegradação, onde: SST I= sólidos suspensos totais no biodigestor I; SST II= sólidos suspensos totais no biodigestor II; SSF I= sólidos suspensos fixos no biodigestor I; SSF II= sólidos suspensos fixos no biodigestor II; SSV I= sólidos suspensos voláteis no biodigestor I e SSV II= sólidos suspensos voláteis no biodigestor II.

\subsection{Comparativo DQO e DBO}

Os resultados comparativos de DQO e DBO entre os biodigestores I e II, demonstraram que: as eficiências de remoção de DQO e DBO foram de 51,0 - 61,6\% para o biodigestor I e 26,9 - 43,8\% para o biodigestor II, respectivamente (Figura 5). Verificou-se baixa redução na carga orgânica no período do teste no biodigestor II (concentração 1:1), (SOUZA, 2001). Para melhor eficiência de remoção de carga orgânica e para a temperatura imposta ao substrato, seria necessário adotar maiores tempos de retenção hidráulica e/ou reduzir a carga orgânica do substrato (diluição do substrato), justificando maior redução no biodigestor I (concentração 1:2). Esta baixa redução de DQO e DBO no biodigestor II não acompanhou a redução de sólidos voláteis, isto pode ter ocorrido devido à presença de muitas fibras o substrato contenha muitas fibras que não são facilmente degradáveis pelos microorganismos, exigindo maior tempo de retenção. 


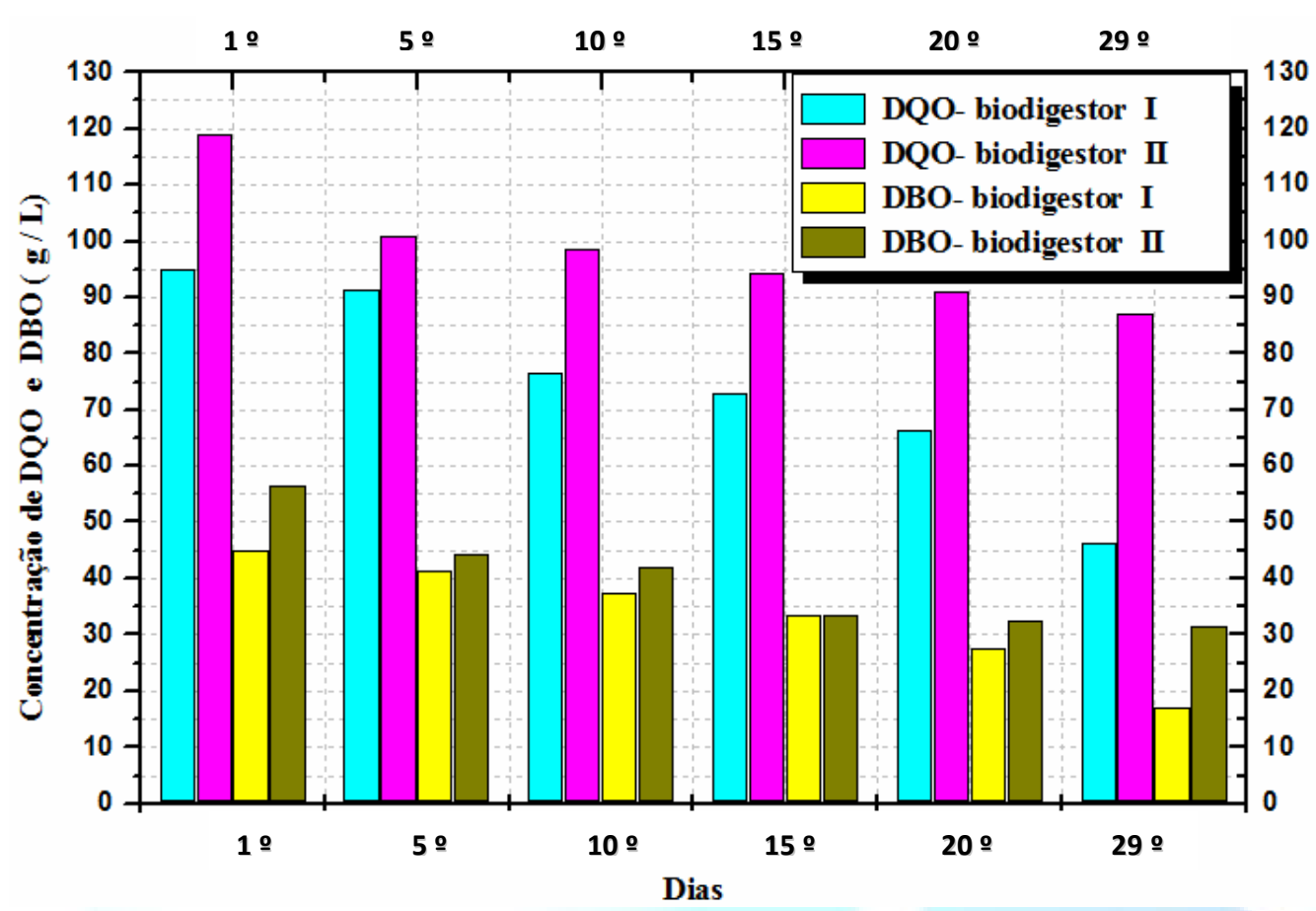

Figura 5. Valores de DQO e DBO nos biodigestores I e II durante o período de biodegradação.

\subsection{Relação Alcalinidade - Ácidos Orgânicos Voláteis e pH}

A Figura 6 contem os resultados comparativos obtidos entre a alcalinidade, ácidos orgânicos voláteis (AOV) e $\mathrm{pH}$ nos biodigestores I e II. Observou-se que aproximadamente no $10^{\circ}$ dia houve acumulo de AOV e consumo expressivo de alcalinidade baixando o $\mathrm{pH}$ para $<6,0$, porém não houve necessidade de correção do $\mathrm{pH}$, pois o sistema foi restabelecendo naturalmente nos próximos dias. Esta variação ocorreu pelo acúmulo de ácidos orgânicos voláteis no reator consumindo alcalinidade e conseqüentemente, diminuindo o $\mathrm{pH}$ desestabilizando o processo. Para evitar essa variação, recomenda-se uma proporção de 10:1 (CHERNICHARO, 1997), que não foi obtida em todo o período do estudo (Figura 6). Esta relação garante o bom funcionamento do biodigestor. 


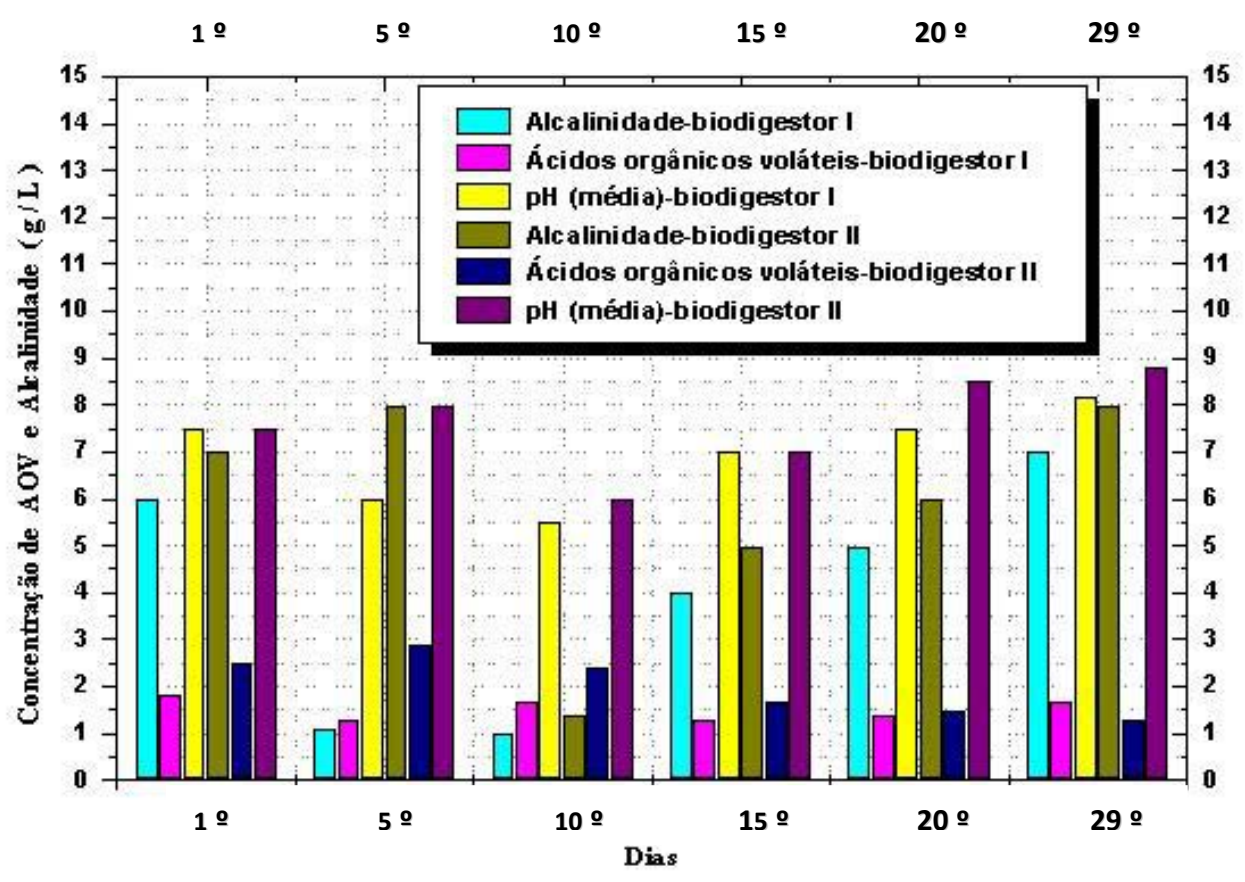

Figura 6. Relação alcalinidade, ácidos orgânicos voláteis e pH nos biodigestores I e II durante o período de biodegradação.

\subsection{Atividade Metanogênica Específica}

Os resultados do teste de Atividade Metanogênica Específica -AME, onde os valores para o biodigestor I e II referente ao volume de gás metano produzido nas CNTP foram de 36 e $17 \mathrm{~mL} \mathrm{CH} \cdot \mathrm{g}^{-1} \mathrm{SSV} \cdot \mathrm{h}^{-1}$, respectivamente, sendo que o biodigestor I apresentou cerca de 2 vezes mais atividade em relação ao biodigestor II (Tabela 4).

A AME da biomassa avaliada demonstrou eficácia em converter os substratos em biogás nas condições estabelecidas neste estudo. A utilização do método volumétrico de medição direta do volume de metano (SOUTO et al., 2007) produzido foi de grande vantagem, além de indicar a capacidade geradora de gás metano em estrume bovino em relação aos sólidos suspensos voláteis/hora, essa metodologia dispensa a utilização de cromatógrafo, para a determinação da medição de biogás e pode ser realizado periodicamente, com intuito de tomar medidas de correção para melhorar o desempenho do processo. 
Tabela 4 - Atividade Metanogênica Específica máxima com tempo de incubação de 29 dias, para produção de biogás utilizando estrume bovino (AME)

\begin{tabular}{cccccc}
\hline BIODIGESTOR & $\begin{array}{c}\text { Produção } \\
\text { Gás mL (29dias) }\end{array}$ & $\begin{array}{c}\text { SSVi(1) } \\
\left(\mathbf{g} \cdot \mathbf{L}^{-1}\right)\end{array}$ & $\begin{array}{c}\text { Biomassa } \\
\text { ou CSSVT } \\
\left(\mathbf{g} \cdot \mathbf{L}^{-1}\right)\end{array}$ & $\begin{array}{c}\text { Tempo } \\
\text { Horas }\end{array}$ & $\begin{array}{c}\text { AME(2) } \\
\text { (mL CH4.g } \text { SSV.h }^{-1} \text { ) }\end{array}$ \\
\hline I & 156100 & 61,7 & 6,2 & 696 & 36 \\
II & 111700 & 94,5 & 5,2 & 696 & 17 \\
\hline
\end{tabular}

(1) Sólidos voláteis inicial;

(2) Atividade metanogênica específica.

\section{CONCLUSÕES}

I- Após o período de biodegradação estabelecido neste estudo (29 dias), o volume produzido de biogás foi maior no biodigestor I (diluído na proporção 1:2), evidenciando que a diluição tem um papel fundamental na produção do biogás;

II- A eficiência na remoção de sólidos voláteis foi maior no biodigestor II. A eficiência do processo de bioestabilização anaeróbia da matéria orgânica neste estudo se mostrou relevante para condição mais diluída do estrume (1:2), sendo a melhor condição para o tratamento do resíduo já estabilizado;

III- As variáveis de controle utilizadas para realização do presente estudo mostraramse adequadas, assim como o uso do teste de AME. O biodigestor I apresentou cerca de 2 vezes mais atividade em relação ao biodigestor II, evidenciando mais uma vez que a diluição do substrato tem um papel fundamental na produção do biogás.

\section{REFERÊNCIAS}

APHA, AWW, WEF. Standard methods for the examination of water and wastewater. $21^{\text {th }}$. Edition. American Public Health Association, Washingtion, DC., 2005.

BATISTA, L.F. Manual Técnico: Construção e operação de biodigestores modelo Indiano. Brasília, DF: Embrater, 1981.

CHERNICHARO, C.A. L. Biomassa nos Sistemas Anaeróbios. In: CHERNICHARO, C. A L. Princípios do Tratamento Biológico de Águas

Residuárias: reatores anaeróbios. Belo Horizonte- Br: Departamento de Engenharia Sanitária e Ambiental-DESA, Universidade Federal de Minas GeraisUFMG, 1997. v. 5, p. 85-88, cap.3.

DOHÁNYOS, M.; ZÁBRANSKÁ, J. Anaerobic digestion, In: SPINOSA, L.; VESILIND P. A. Sludge into biosolids. UK: IWA Publishing, 2001, p. 223-241 
FORESTI, E. Fundamentos do processo de digestão anaeróbia. In: TALLER Y SEMINARIO LATINOAMERICANO, 3., 1994, Montevideo. Anais... Montevideo, Uruguai, 1994.

LUCAS JR., J.; ORTOLANI, A.F.; BENINCASA, M.; YMADA, R.Y. Avaliação do uso de inóculo no desempenho de biodigestores abastecidos com estrume de frangos de corte com cama de maravalha. In: CONGRESSO BRASILEIRO DE ENGENHARIA AGRÍCOLA, XXII, Anais... Ilhéus: SBEA, CEPLAC, 1993 p.91530 .

\section{LUCAS JR., J., SANTOS, T.M.B. APROVEITAMENTO DE RESÍDUOS DA} INDÚSTRIA AVÍCOLA PARA PRODUÇÃO DE BIOGÁS. In: Simpósio sobre Resíduos da Produção Avícola 12 de abril de 2000- Concórdia, SC.

LUCAS JR., J.; SILVA, F.M. Aproveitamento de resíduos agrícolas para a geração de energia. In: CONGRESSO BRASILEIRO DE ENGENHARIA AGRÍCOLA, 27. Poços de Caldas. Anais... Lavras/MG: UFLA, SBEA, 1998. P.63-67.

MONTEgGiA, L. O. Proposta de Metodologia para Avaliação do ParâmetroAtividade Metanogênica Específica. CONGRESSO BRASILEIRO DE ENGENHARIA, 1997.

\section{NASCIMENTO, E.F. BIODIGESTÃO ANAERÓBIA: Efeito do tempo de} retenção hidráulica e recirculação do efluente, em substrato com estrume de suínos. 1995. 86 f. Dissertação (Mestrado em Agronomia/Energia na Agricultura)Faculdade de Ciências Agronômicas, Universidade Estadual Paulista, Botucatu, 1995.

PROSAB - PROGRAMA DE PESQUISAS EM SANEAMENTO BÁSICO EDITAL 03 Digestão de resíduos sólidos orgânicos e aproveitamento do biogás.

Coordenador: Sérvio Túlio Cassini. Editora: ABES, RIMA-Rio de Janeiro, 210p., 2003.

SOARES, H. M., HIRATA, Y. S. Práticas de Laboratório. CURSO DE TRATAMENTO BIOLÓGICO DE RESÍDUOS, 3, Florianópolis - 30 de junho a 11 de julho de 1997. Anais.... Florianópolis-Br. p.13, 1997.

SOUTO, F. S., AQUINO, S., CHERNICHARO, C. A. L.; "Avaliação da influência das condições de incubação no teste de atividade metanogênica específica (AME) de lodos anaeróbios". Assoc. Bras. Eng. Sanit. Amb., p. 1-8, 2007. 
SOUZA, C. F. Biodigestão anaeróbia de dejetos de suínos: "obtenção de dados e aplicação no desenvolvimento de um modelo dinâmico de simulação da produção de biogás. 2001. 140 f. Tese (Doutorado em Zootecnia - Produção Animal) - Universidade Estadual Paulista, Jaboticabal, 2001.

SPERLING, M.V. PRINCÍPIOS DO TRATAMENTO BIOLÓGICO DE ÁGUAS RESIDUÁRIAS. In: Princípios Básicos do Tratamento de Esgotos. Belo Horizonte- Br: Departamento de Engenharia Sanitária e Ambiental- DESA, Universidade Federal de Minas Gerais- UFMG, v.2.1996. 